УДК 544.77:615.47

ИЗУЧЕНИЕ ФИЗИКО-ХИМИЧЕСКИХ СВОЙСТВ И ОПРЕДЕЛЕНИЕ КРИТИЧЕСКОЙ КОНЦЕНТРАЦИИ МИЦЕЛЛООБРАЗОВАНИЯ МНОГОКОМПОНЕНТНЫХ ДЕЗИНФИЦИРУЮЩИХ СРЕДСТВ «ДЕЗОМИКС-П» И «ФРИСЕПТ-ГАММА»

Перевалов С.Г., Катаева Н.Н., Царегородцева А.А.

ФГБОУ ВО «Уральский государственный медииинский университет» Минздрава России, Екатеринбург, е-mail: perevalovsg@mail.ru

На сегодняшний день многокомпонентные моющие дезинфицирующие средства широко используются в различных лечебно-профилактических учреждениях. Актуальной является проблема совершенствования качественного и количественного состава смесей дезсредств разного спектра действия. Важным этапом разработки и улучшения состава дезинфицирующих растворов является изучение их физико-химических свойств. В статье приведены результаты исследования некоторых физико-химических параметров водных растворов многокомпонентных дезинфицирующих средств «Дезомикс-п» и «Фрисепт-Гамма». На основе экспериментальных данных построены графики зависимостей водородного показателя, удельной электропроводности, поверхностного натяжения и осмомоляльности исследуемых растворов от их объемной концентрации в интервале $0,05-2 \%$. По результатам анализа графиков определены точки перегибов на кривых зависимостей, соответствующие критической концентрации мицеллообразования (ККМ) поверхностно-активных веществ исследуемых дезинфицирующих средств. Показано, что значения критической концентрации мицеллообразования, найденные разными методами, отличаются незначительно для каждого индивидуального средства в интервале от $0,28 \%$ до 0,42\% (об.). Полученные величины ККМ попадают в концентрационные интервалы практического использования этих дезинфицирующих средств в санитарии (0,01-5\%). Учитывая величины ККМ, можно рекомендовать использование препарата «Дезомикс-п» с концентрацией не менее $0,4 \%$ (объем.) при разработке режима стерилизации изделий медицинского назначения, что не учитывалось ранее в инструкции применения средства. Критические концентрации мицеллообразования исследуемых средств близки по значению с величиной ККМ для чистого гексадецилдиметилбензиламмония хлорида и меньше ККМ для чистого хлоргексидина биглюконата. Это свидетельствует об эффективности этих средств как ПАВ и, как следствие, высокой бактерицидной активности по сравнению с чистым бензалкония хлоридом и хлоргексидина биглюконатом.

Ключевые слова: дезинфицирующие средства, критическая концентрация мицеллообразования, осмомоляльность, поверхностное натяжение, удельная электропроводность

\title{
PHYSICO-CHEMICAL PROPERTIES INVESTIGATION AND CRITICAL MICELLE CONCENTRATIONS DETERMINATION FOR «DEZOMIKS-P» AND «FRISEPT-GAMMA» MULTICOMPONENT DISINFECTANTS
}

Perevalov S.G., Kataeva N.N., Tsaregorodtseva A.A.

Federal State Budget Educational Institution of Higher Education «Ural State Medical University» of the ministry of health of the Russian Federation, Ekaterinburg, e-mail: perevalovsg@mail.ru

Today, multicomponent detergent disinfectants are widely used in various medical institutions. The problem of creating new and improving old multi-component disinfectants of a wide spectrum of activity is relevant. The study of the physicochemical properties of such disinfectant solutions and their components is important stage in the development and improvement of these agents. There are few articles concerning the study of the physicochemical properties of such detergent mixtures in the available literature. This article presents the results of study of some physicochemical properties for aqueous solutions of multicomponent disinfectants «Dezomiks-p» and «FriseptGamma.» The values were experimentally measured and the dependencies of $\mathrm{pH}$, conductivity, surface tension and osmolarity of these disinfectants aqueous solutions on their volume concentration in the range of $0.05-2 \%$ were plotted. Based on the analysis of the plots obtained, the inflection points of these dependencies were determined, corresponding to detergent critical micelle concentration of these disinfectants. It is shown that the critical micelle concentrations found by different methods differ slightly for each individual agent. Both disinfectants have similar critical micelle concentrations in the range from $0.28 \%$ to $0.42 \%$ (vol.). The obtained values of CMC fall within the concentration ranges of the practical use of these disinfectants in sanitation $(0.01 \%-5 \%)$. Given the magnitude of CMC, it is possible to recommend the use of the drug «Desomix-p» with a concentration of at least $0.4 \%$ (vol.) when developing the sterilization regime for medical products, which was not previously taken into account in the instructions for use of the product.

Keywords: disinfectants, critical micelle concentration, osmomolarity, surface tension, specific electrical conductance

Многоцелевые многокомпонентные моющие и дезинфицирующие средства «Дезомикс-п» [1] и «Фрисепт-Гамма» [2] широко применяются в лечебно-профилактических учреждениях. «Дезомикс-п» ис- пользуется в виде водных растворов с концентрацией средства в интервале от 0,05\% до 2\% (объем.) [1], а «Фрисепт-Гамма» - от 0,01\% до $5 \%$ (объем.) [2]. Эти смеси обладают очень широким спектром бактерицидно- 
го, фунгицидного и вирулицидного действия, но применяются только для дезинфекции загрязненных поверхностей, а не кожных покровов и слизистых оболочек, обладая умеренной токсичностью $[1,2]$.

Полезные потребительские свойства данных средств и их растворов определяются их составом - присутствием широкого спектра биологически активных дезинфицирующих веществ осно́вной природы, представляющих собой катионные поверхностно-активные вещества (ПАВ): длинноцепочечные третичные алкиламины, четвертичные аммониевые соли (ЧАС) и соли алкилгуанидиния. Вследствие чего эти средства и их водные растворы обладают всеми физико-химическими свойствами ПАВ и хорошим моющим действием. Основными биологически активными компонентами этих средств являются смеси ЧАС - хлоридов алкилдиметилбензиламмония (бензалкония хлорид, АДМБХ) и соли алкилгуанидиния с длинноцепными алкильными группами $[1,2]$.

Важнейшим параметром растворов ПАВ, определяющим его эффективность как моющего и бактерицидного средства, является критическая концентрация мицеллообразования (ККМ) - минимальная концентрация его раствора, при которой начинается образование мицелл из молекул/ионов ПАВ. Известно, что бактериостатическая и бактерицидная активность растворов ЧАС типа бензалкония хлорида в отношении большинства бактерий пропорциональна величинам их ККМ [3]. Механизмы действия ЧАС неспецифичны: за счет своей поверхностной активности и наличия положительного заряда эти катионные ПАВ даже при очень низких концентрациях в растворах электростатически взаимодействуют с фосфолипидами и белками биомембран, нарушая мембранную проницаемость, процессы транспорта и энергообеспечения живых клеток и способны вызывать их апоптоз [3-5]. При концентрациях растворов выше ККМ растворы ПАВ эффективно стабилизируют эмульсии типа масло/вода, что объясняет их моющую способность [6]. Кроме того, такие растворы ПАВ способны даже разрушать мембраны живых клеток, солюбилизируя их эмульгированием. Бактериостатическое действие дезинфицирующих средств начинается при концентрациях, намного более низких, чем ККМ $[3,4]$, поскольку достаточно небольших концентраций эффективных катионных ПАВ, вхо- дящих в состав изучаемых средств, чтобы критически нарушить проводимость клеточных мембран. Этот факт является причиной токсичности подобных веществ для клеток живых организмов.

Изучение поведения смесей ПАВ в растворах и определение их ККМ тесно связано с разработкой практических методик антисептики в медицине, поскольку индивидуальные ПАВ смесей сложным образом влияют на физико-химические и биологические свойства растворов, например на величины ККМ [5] и минимальных ингибирующих концентраций (МИК) по отношению к микроорганизмам [3, 4]. Синергические соотношения биологического действия между некоторыми ПАВ в растворах позволяют снижать их концентрации, делая методики антисептики и дезинфекции более эффективными и дешевыми.

Существует много методов определения ККМ индивидуальных ПАВ. Все они основаны на резком изменении различных физико-химических свойств растворов ПАВ (светопропускания, показателя преломления, осмотического давления, поверхностного натяжения, электропроводности и др.) при переходе от молекулярного раствора к мицеллярному. Концентрации растворов ПАВ, при которых наблюдаются перегибы/ изломы на графиках «свойство - концентрация» соответствуют ККМ.

Цель исследования: изучить зависимость некоторых физико-химических свойств растворов многокомпонентных дезинфицирующих средств «Дезомикс-п» и «Фрисепт-Гамма» от их концентрации; выяснить возможность определения критических концентраций мицеллобразования в сложных смесях ПАВ разной природы, используя методы определения ККМ, применимые для индивидуальных ПАВ.

\section{Материалы и методы исследования}

В работе были определены зависимости $\mathrm{pH}$, поверхностного натяжения, удельной электропроводности и осмомоляльности разбавленных растворов этих дезинфицирующих средств от концентрации - объемной доли $(\varphi, \%)$.

Поверхностное натяжение измеряли сталагмометрическим методом, $\mathrm{pH}$ растворов устанавливали с помощью рН-метра со стеклянным электродом «рН-150МИ» (ООО «Измерительная техника», Москва; погрешность измерения $\pm 0,05)$. Определение удельной электропроводности производили на кондуктометре «Анион 7020» 
(ООО НПП «Инфраспак-Аналит», Новосибирск; погрешность измерения $\pm 4 \%$ $\mathrm{мCM} / \mathrm{cm}$ ), осмомоляльность устанавливали, используя осмометр криоскопический медицинский «ОСКР-1М» («КИВИ осмометрия», Санкт-Петербург, погрешность измерения \pm 2 ммоль/кг $\mathrm{H}_{2} \mathrm{O}$ ). Графики зависимостей «свойство - концентрация» строили в программе Microsoft Excel.

\section{Результаты исследования и их обсуждение}

Критическую концентрацию мицеллообразования определяют по той точке, которая соответствует излому на кривых зависимостей свойств растворов от концентрации. Считается, что при концентрациях, меньших ККМ в растворах ПАВ, присутствуют лишь молекулы/ионы и зависимость любого свойства определяется именно концентрацией молекул/ионов. При образовании мицелл в растворах свойство будет претерпевать резкое изменение в связи со скачкообразным увеличением размера растворенных частиц [6].

Результаты взаимосвязи свойств исследуемых растворов от концентрации в интервале от $0,05 \%$ до 2,0\% приведены на рис. 1-4. Графики зависимостей каждого отдельно взятого физико-химического параметра (pH, поверхностного натяжения, электропроводности и осмомоляльности) от объемной доли раствора $(\varphi, \%)$ выглядят аналогично для обоих дезинфицирующих средств, отличаясь лишь количественно, несмотря на различный состав этих смесей $[1,2]$. Все растворы имеют слабощелочную реакцию среды (рис. 1), способствующую подавлению жизнедеятельности кислотоустойчивых микроорганизмов (в том числе возбудителей туберкулеза и кандидоза), повышению растворимости и проявлению поверхностной активности компонентами средств.

Величины $\mathrm{pH}$ обоих средств при увеличении концентрации их растворов от $0,2 \%$ до $2 \%$ возросли незначительно (от 8,37 до 8,96 у «Дезомикс-п» и от 9,34 до 9,73 у «Фрисепт-Гамма). Такое изменение $\mathrm{pH}$ обусловлено наличием в составе дезинфицирующих средств слабых электролитов, таких как третичные амины. Небольшое изменение $\mathrm{pH}$ этих растворов после первоначального скачка $\mathrm{pH}$ в интервале $0-0,2 \%$, обусловленного поведением сильно разбавленного раствора, не позволяет надежно определить значение ККМ растворов по кривым зависимости $\mathrm{pH}$ от $\varphi(\%)$ (рис. 1).

На кривых зависимостей электропроводности от $\varphi$ (рис. 2) обоих средств можно увидеть резкий спад приращения электропроводности растворов за точками излома при $\varphi$ около $0,3 \%$, что обусловлено понижением подвижности мицелл в электрическом поле по сравнению с отдельными ионами [6].

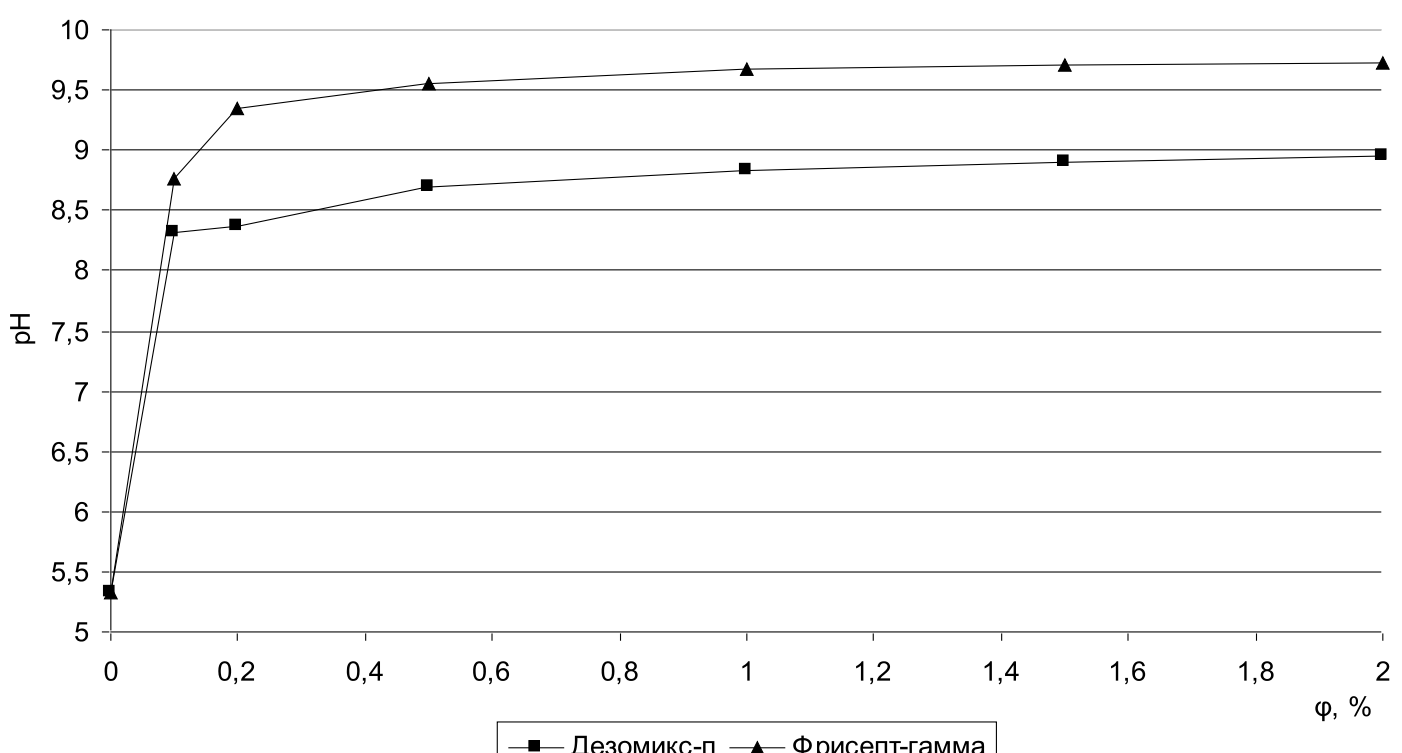

Рис. 1. График зависимости рН от концฺентращчии растворов дезинфицирующих средств 


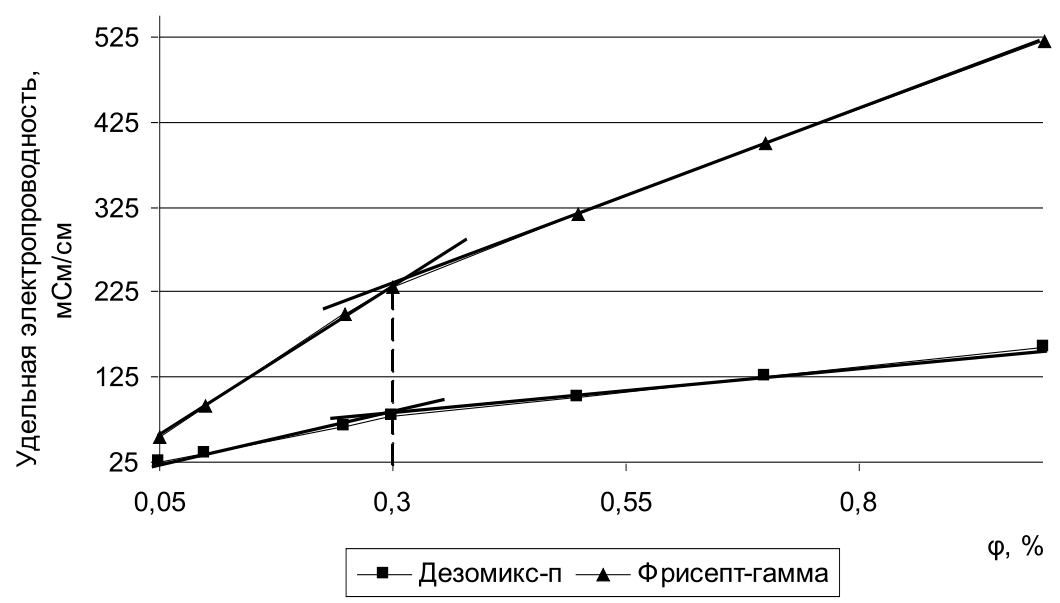

Рис. 2. График зависимости удельной электропроводности от концентрациии растворов дезинфицирующих средств

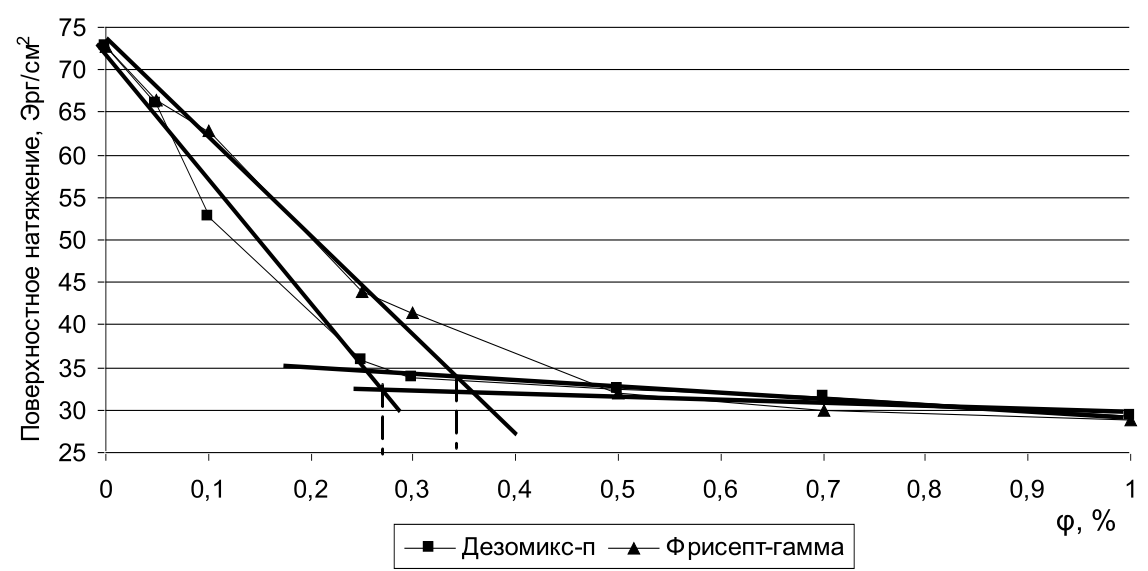

Рис. 3. Изотермы поверхностного натяжения растворов дезинфицирующих средств при комнатной температуре

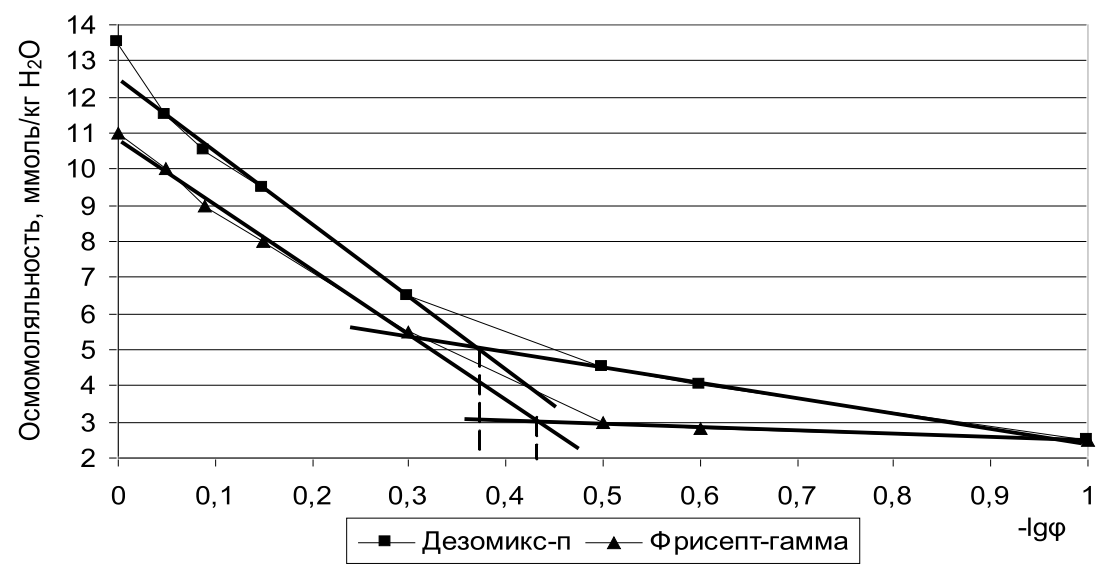

Рис. 4. График зависимости осмомоляльности от отрицательного десятичного логарифма кониеентрации растворов дезинфиичирующих средств 
Изотерма поверхностного натяжения (рис. 3) и графики зависимости осмомоляльности от $-\lg \varphi$ (рис. 4) имеют перегибы, наличие которых объясняется мицеллообразованием ПАВ в этих растворах. При переходе истинного раствора ПАВ в коллоидно-мицеллярный поверхностное натяжение и осмомоляльность перестают значительно меняться при увеличении концентрации, так как мицеллы практически не обладают осмотической и поверхностной активностью.

При этом для катионных ПАВ точка излома более резко выявляется на графике, построенном в координатах: осмомоляльность/$\lg \varphi$. Точки перегибов на графике (рис. 4): $-\lg \varphi=0,38 ;-\lg \varphi=0,43$ соответствуют объемной доле растворов $0,42 \%$ и $0,37 \%$.

Величины ККМ, соответствующие точкам излома, несколько различаются в зависимости от метода их определения, в то время как у однокомпонентных растворов, например у водного раствора хлоргексидина биглюконата, они были одинаковыми [5] (таблица). Так, у растворов «Дезомикс-п» ККМ составляют 0,$3 ; 0,28$ и $0,42 \%$ при определении (из кривых зависимостей) по удельной электропроводности, по поверхностному натяжению и осмомоляльности растворов (зависимость от $-\lg \varphi$ ) соответственно. А у растворов «Фрисепт-Гамма» они составляют 0,3; 0,34 и 0,37\% при определении по удельной электропроводности, по поверхностному натяжению и осмомоляльности растворов (зависимость от $-\lg \varphi$ ), соответственно. По данным графиков (рис. 4) можно лишь приблизительно определить общую осмомоляльную концентрацию всех компонентов изучаемых средств в точке ККМ: для «Дезомикс-п» она составляет примерно 5 ммоль/кг $\mathrm{H}_{2} \mathrm{O}$, для «Фрисепт-Гамма» - 3 ммоль/кг $\mathrm{H}_{2} \mathrm{O}$. Учитывая состав этих средств $[1,2]$ и экспериментальные данные (рис. 4), можно рассчитать содержание смесей ЧАС в растворе в точках ККМ как 0,513 ммоль/л и 0,925 ммоль/л для «Дезомикс-п» и «Фрисепт-Гамма» соответственно. Анализ литературных данных по величинам ККМ индивидуальных АДМБХ [7] и хлоргексидина биглюконата [8] позволяет заключить, что ККМ ЧАС в исследуемых средствах близки по значению с величиной ККМ для чистого гексадецилдиметилбензиламмония хлорида и меньше ККМ для чистого хлоргексидина биглюконата (таблица). Это свидетельствует об эффективности этих средств как ПАВ и, как следствие, высокой бактерицидной активности [3] по сравнению с чистым бензалкония хлоридом и хлоргексидина биглюконатом. Полученные величины ККМ попадают в концентрационные интервалы практического использования этих дезинфицирующих средств в санитарии (0,01-5\%). Причем при более низких концентрациях (менее 0,2\%) проявляется преимущественно бактериостатическое и микостатическое действие, а при более высоких - действие против микобактерий туберкулеза и способность отмывать различные поверхности, загрязненные сильно зараженными биологическими материалами - кровью, мокротой, фекалиями.

Поскольку для препарата «Дезомикс-п» не имеется режима стерилизации изделий медицинского назначения [1], то, учитывая полученные данные, можно рекомендовать при разработке такого режима использовать раствор этого препарата с концентрацией не менее $0,4 \%$ (объем.). Небольшие различия между значениями ККМ обусловлены, вероятно, взаимодействием между молекулами разных ПАВ в процессе мицеллобразования и погрешностями эксперимента, и выяснение этого требует дальнейших исследований.

Значения ККМ индивидуальных ПАВ и смесей ЧАС

\begin{tabular}{|l|c|c|}
\hline \multicolumn{1}{|c|}{ Вещество } & ККМ, ммоль/л & Литература \\
\hline Додецилдиметилбензиламмония хлорид & $8,837^{\text {a }}$ & {$[7]$} \\
\hline Тетрадецилдиметилбензиламмония хлорид & $1,970^{\text {a }}$ & {$[7]$} \\
\hline Гексадецилдиметилбензиламмония хлорид & $0,493^{\text {a }}$ & {$[7]$} \\
\hline Хлоргексидина биглюконат & $16,90^{\text {б }}$ & {$[8]$} \\
\hline Смесь ЧАС в «Дезомикс-п» & $0,513^{\text {в }}$ & {$[1]$} \\
\hline Смесь ЧАС в «Фрисепт-Гамма» & $0,925^{\text {в }}$ & {$[2]$} \\
\hline
\end{tabular}

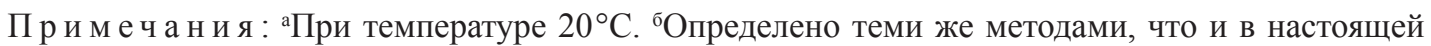

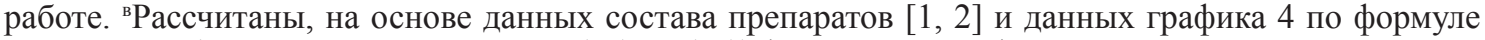
ККМ $=100 \times($ содержание в препарате $(\%) \times \varphi(\%)) / 360$, где 360 г/моль - средняя молярная масса смеси ЧАС (бензалкония хлорида). 


\section{Выводы}

1. В результате измерения ряда физикохимических показателей водных растворов «Дезомикс-п» и «Фрисепт-Гамма» разной концентрации при постоянной температуре были определены значения ККМ растворов исследуемых дезинфицирующих средств. Показано, что значения ККМ, найденные разными методами, отличаются незначительно для каждого индивидуального средства; оба дезинфицирующих средства имеют близкие значения ККМ в интервале от $0,28 \%$ до $0,42 \%$ (объем.).

2. Полученные величины ККМ исследуемых средств могут быть учтены на практике для приготовления растворов, например, при разработке режима стерилизации изделий медицинского назначения, что не учитывалось ранее в инструкции применения средства «Дезомикс-П».

\section{Список литературы / References}

1. Дезомикс-п: информация [Электронный ресурс]. URL: http://dezr.ru/preparat/dezomiks-p (дата обращения: 16.12.2018)

Desomiks-p: informaciya [Electronic resource]. URL: http://dezr.ru/preparat/dezomiks-p (date of access: 16.12.2018) (in Russian).

2. Фрисепт-гамма: информация [Электронный ресурс]. URL: http://dezr.ru/preparat/frisept-gamma (дата обращения: 16.12.2018).
Frisept-gamma: informaciya [Electronic resource]. URL: http://dezr.ru/preparat/frisept-gamma (date of access: 16.12.2018) (in Russian)

3. Edited by Fraise Adam, Maillard Jean-Yves, Sattar Syed. Russel, Hugo\&Ayliffe's Principles and Practice of Disinfection, Preservation and Sterilization. Wiley-Blackwell. $5^{\text {th }}$ edition. 2013. 618 p.

4. McDonnell Gerald E. Antisepsis, Disinfection, and Sterilization: Types, Action, and Resistance. ASM Press. $2^{\text {nd }}$ edition. 2017. $432 \mathrm{p}$.

5. Ляпунов Н.А., Пуртов А.В. Исследование поверхностно-активных и коллоидно-мицеллярных свойств бензалкония хлорида // Фармаком. 2009. № 4. С. 54-58.

Lyapunov N.A., Purtov A.V. Study of surfactant and colloid-micellar characteristics of benzalconium chloride // Farmacom. 2009. № 4. P. 54-58 (in Russian).

6. Волков В.А. Коллоидная химия. Поверхностные явления и дисперсные системы. СПб.: Лань, 2015. 672 с.

Volkov V.A. Colloid chemistry. Surface phenomena and disperse systems. St.-Petersburg: Lan', 2015. 672 p. (in Russian).

7. Vitkova Z., Oremusova J., Herdova P., Ivankova O., Vitko A. Association, Distribution, Liberation, and Rheological Balances of Alkyldimethylbenzylammonium Chlorides (C12C16). Molecules. 2017. Vol. 22. № 10. P. 1802-1816. DOI: 10.3390/molecules22101802.

8. Охотникова А.А., Данилов Д.Ю., Катаева Н.Н. Определение критической концентрации мицеллообразования хлоргексидина // Актуальные вопросы современной медицинской науки и здравоохранения: материалы II Международной (72 Всероссийской) научно-практической конференции молодых ученых и студентов (12-14 апреля 2017 г.). Екатеринбург, 2017. Т. 3. С. 608-611.

Ohotnikova A.A., Danilov D.Yu., Kataeva N.N. Determination of critical concentration of miscellaneous formation of chloroxexidine // Aktualnye voprosy' sovremennoy meditsinskoy nauki i zdravoohraneniya: materialy` II Mezhdunarodnoy (72 Vserossiiskoy) nauchno-prakticheskoy konferencii molodykh uchyonych I studentov (12-14 aprelya 2017). Ekaterinburg, 2017. T. 3. P. 608-611 (in Russian). 